\title{
D-cycloserine potentiates the reconsolidation of cocaine-associated memories
}

\author{
Jonathan L.C. Lee, ${ }^{1,2}$ Richard J. Gardner, Victoria J. Butler, and Barry J. Everitt \\ Behavioural and Clinical Neuroscience Institute, Department of Experimental Psychology, University of Cambridge, \\ Cambridge CB2 3EB, United Kingdom
}

\begin{abstract}
Conditioned cue-induced relapse to drug seeking is a major challenge to the treatment of drug addiction. It has been proposed that D-cycloserine might be useful in the prevention of relapse by reducing the conditioned reinforcing properties of drug-associated stimuli through facilitation of extinction. Here we show that intrabasolateral amygdala infusions of D-cycloserine in fact potentiate the reconsolidation of stimulus-cocaine memories to increase cue-induced relapse to drug seeking in rats with an extensive drug self-administration history. This elevation of cocaine seeking was correlated with an increase in the expression of the reconsolidation-associated gene zif268.
\end{abstract}

Drug addiction is often described as a chronic relapsing disorder, in which craving and relapse to drug seeking occur even after prolonged abstinence (Gawin and Kleber 1986; Lu et al. 2004). A major contributor to relapse is exposure to environmental stimuli that have previously been associated regularly with the effects of self-administered drugs of abuse. Such drug-associated stimuli induce craving in abstinent addicts, and precipitate relapse to drug seeking (Gawin and Kleber 1986; Ehrman et al. 1992; O'Brien et al. 1998; Childress et al. 1999). In experimental animals, a conditioned stimulus (CS) paired repeatedly with self-administered cocaine similarly induces relapse to drug seeking (de Wit and Stewart 1981; Fuchs et al. 1998; Grimm et al. 2001).

The basolateral amygdala (BLA) is a primary locus of CS-US (unconditioned stimulus) associations (LeDoux 2000; Everitt et al. 2003), and is critical for the control of goal-directed behavior by conditioned reinforcers (Burns et al. 1993; Corbit and Balleine 2005). Furthermore, lesions of the BLA disrupt conditioned cueinduced reinstatement of drug seeking (Meil and See 1997) and the acquisition of drug seeking under a second-order schedule of reinforcement (Whitelaw et al. 1996). The infusion of antisense oligodeoxynucleotides targeting the immediate-early gene zif268 (also known as EGR1, Krox24, and NGFI-A) into the BLA impairs the reconsolidation of CS-cocaine associations and thereby reduces cue-induced cocaine seeking and relapse (Lee et al. 2005, 2006a). Memory reconsolidation is the process that is hypothesized to restabilize memories following their reactivation through stimulus re-exposure (Nader 2003), the disruption of which both results in amnesia and has been proposed to be a potential treatment strategy for neuropsychiatric disorders, such as post-traumatic stress and drug addiction in which persistent maladaptive memories play an important role (Lee et al. 2005; Brunet et al. 2007).

An alternative therapeutic approach for such disorders is to use cognitive enhancement strategies to potentiate the extinction of the maladaptive memories (Ressler et al. 2004; Richardson et al. 2004). The partial $N$-methyl-D-aspartate (NMDA) receptor agonist D-cycloserine (DCS) potentiates extinction in aversive and appetitive tasks when administered both systemically and directly into the BLA (Walker et al. 2002; Ledgerwood et al. 2003; Botreau et al. 2006). However, under certain conditions intra-BLA DCS can increase, rather than reduce, subsequent fear memory expression

\footnotetext{
'Present address: School of Psychology, University of Birmingham, Edgbaston, Birmingham B15 2TT, UK. ${ }^{2}$ Corresponding author.

E-mail j.l.c.lee@bham.ac.uk; fax 441214144897.
}

Article is online at http://www.learnmem.org/cgi/doi/10.1101//m.1186609
(Lee et al. 2006b). This finding is consistent with a potentiation of fear memory reconsolidation, and predicts that DCS might also enhance drug memories, which would be a potentially major limitation in a therapeutic setting. Therefore, using conditions that have been previously demonstrated to engage drug memory reconsolidation in a translational model of cocaine seeking (Lee et al. 2006a); we investigated whether or not DCS infusion into the BLA would enhance memory reconsolidation to increase cocaine seeking. Also investigated was the expression of zif268 in the amygdala following DCS treatment and CS re-exposure since this plasticity gene provides a cellular correlate of memory reconsolidation (Lee et al. 2005).

The subjects were 45 adult male Lister hooded rats, weighing $280-350 \mathrm{~g}$. They were housed in pairs prior to surgery, and singly thereafter, in holding rooms maintained at $21^{\circ} \mathrm{C}$ on a reversedlight cycle (12 h light:12 h dark; lights on at 19:00). After recovery from surgery, food was restricted to $20 \mathrm{~g} /$ day. Water was freely available throughout the experiment. All procedures were conducted in accordance with the UK 1986 Animals (Scientific Procedures) Act (Project License PPL 80/1767). Rats were implanted with a single catheter in the right jugular vein, and also with bilateral chronic indwelling guide cannulae targeting the BLA. The coordinates for cannulae implantation were (relative to bregma): $\mathrm{AP}-2.6$; $\mathrm{ML} \pm 4.5 ; \mathrm{DV}-5.6$ (from dura). Details of the intravenous and stereotaxic surgical procedures are described elsewhere (Di Ciano and Everitt 2001). A minimum of 7 d was allowed before behavioral training and testing began.

All behavioral procedures were carried out in operant chambers (Med Associates) as previously described (Di Ciano and Everitt 2001), and were based on previous experiments (Lee et al. 2006a). Rats underwent $10 \mathrm{~d}$ of cocaine self-administration training under a fixed-ratio-1 (FR1) schedule of reinforcement. At the start of each self-administration session, two levers were inserted into the operant chamber and the house light was illuminated. Each response on the active lever (counterbalanced left or right) was reinforced with a single infusion of i.v. cocaine $(0.25 \mathrm{mg}$ in $0.1 \mathrm{~mL}$ over $5 \mathrm{~s}$ per infusion), accompanied by a 20-s illumination of the CS light located above the active lever, during which both levers were retracted and the house light was extinguished. Responses on the other, inactive, lever had no programmed consequence. To prevent accidental overdose, rats were limited to 30 infusions per hour in the 3-h sessions. In the event of 30 infusions being received, the levers were retracted and the house light extinguished until an hour had elapsed, after which the levers were again extended and the house light illuminated. 
The memory for the CS-cocaine association was reactivated in a single 30-min session through 30 noncontingent presentations of the CS light (20 s; 40-s ISI). No levers were present during the reactivation session, which took place $3 \mathrm{~d}$ after the completion of self-administration training, and $20 \mathrm{~min}$ following infusion of DCS (Sigma, UK; $20 \mu \mathrm{g} / \mu \mathrm{L}$; $0.5 \mu \mathrm{L} /$ side; $0.25 \mu \mathrm{L} / \mathrm{min}$ ) or phosphate buffered saline (PBS) into the BLA as described previously (Lee et al. 2006b). The absence of the levers should decrease the probability of substantial reactivation of the instrumental memory. Nonreactivated groups were infused with DCS and then returned immediately to the home cage without a behavioral test session.

Testing, which took place $6 \mathrm{~d}$ after self-administration training, involved the levers again being extended into the operant chamber and assessed the impact of the CS upon instrumental responding after 6-d abstinence as a model of cue-induced relapse. A response on the active lever was reinforced by a 1-s presentation of the CS light, during which the house light was extinguished, and a response on the inactive lever again had no programmed consequence. There were no cocaine infusions, and the number of lever presses was recorded in a 60-min session. The rats were subsequently retested on the following day.

After completion of behavioral testing, the rats were perfused and their brains cut to produce $60 \mu \mathrm{m}$ coronal sections, which were stained with cresyl violet. Assessment was conducted under light microscopy, and subjects were only included in the statistical analysis if the injectors were located bilaterally within the BLA, and there was no bilateral damage to the amygdala or any other area of the brain (5 rats were excluded on this basis). Fourteen rats were killed by carbon dioxide inhalation $2 \mathrm{~h}$ after memory reactivation (or at the same time point following infusions and nonreactivation). Their brains were extracted, the BLA microdissected bilaterally, and the samples frozen on dry ice and stored at $-80^{\circ} \mathrm{C}$ prior to the quantification of zif 268 protein levels through Western blot analysis as described previously (Lee et al. 2005).

All rats included in the behavioral analyses had cannulae placed bilaterally in the BLA (Fig. 1). There was no difference between any of the groups during cocaine self-administration training and on average rats received 505 pairings of the light CS with an infusion of cocaine (data not shown; Condition $\times$ DCS: $F<1$ ).

Infusion of DCS into the BLA before drug cue re-exposure elevated subsequent active lever responding in a reactivationdependent manner (Fig. 2). For the first test, ANOVA revealed a significant DCS $\times$ Reactivation $\times$ Lever interaction $\left(F_{(1,22)}=8.62\right.$; $P<0.01)$, as well as a significant DCS $\times$ Reactivation interaction $\left(F_{(1,22)}=4.71 ; P<0.05\right)$. The effect was specific to the reactivated condition, as DCS infusion had no impact upon the nonreactivated condition $(F \mathrm{~s}<1)$. This was confirmed by a significant DCS $\times$ Lever interaction $\left(F_{(1,13)}=13.12 ; P<0.01\right)$ for the reactivated condition, and a significant main effect of DCS $\left(F_{(1,13)}=9.66 ; P<\right.$ $0.01)$, but no effect of DCS on inactive lever presses $(F<1)$. The DCS-induced elevation of responding was again observed $24 \mathrm{~h}$ later in test $2\left(\mathrm{DCS} \times\right.$ Reactivation $\times$ Lever: $\left.F_{(1,22)}=4.44 ; P<0.05\right)$, indicating a persistent potentiation of responding, and an overall analysis revealed no difference in the effect of DCS between tests 1 and 2 (DCS $\times$ Reactivation $\times$ Lever: $F_{(1,13)}=7.41 ; P<0.02$; DCS $\times$ Reactivation $\times$ Lever $\times$ Test: $\left.F_{(1,22)}=1.66 ; P>0.21\right)$.

Infusion of DCS into the BLA before drug cue re-exposure potentiated the subsequent expression in the BLA of zif268 protein levels $2 \mathrm{~h}$ after the reactivation session as measured by Western blotting analysis (Fig. 3). ANOVA revealed a significant effect of DCS when infused prior to memory reactivation $\left(F_{(1,6)}=\right.$ 9.42; $P<0.03)$. However, there was no effect of DCS treatment when infused in the absence of memory reactivation $\left(F_{(1,4)}=1.41\right.$; $P>0.30)$.

The present results demonstrate that infusion of the partial NMDA receptor agonist DCS into the BLA shortly before re-

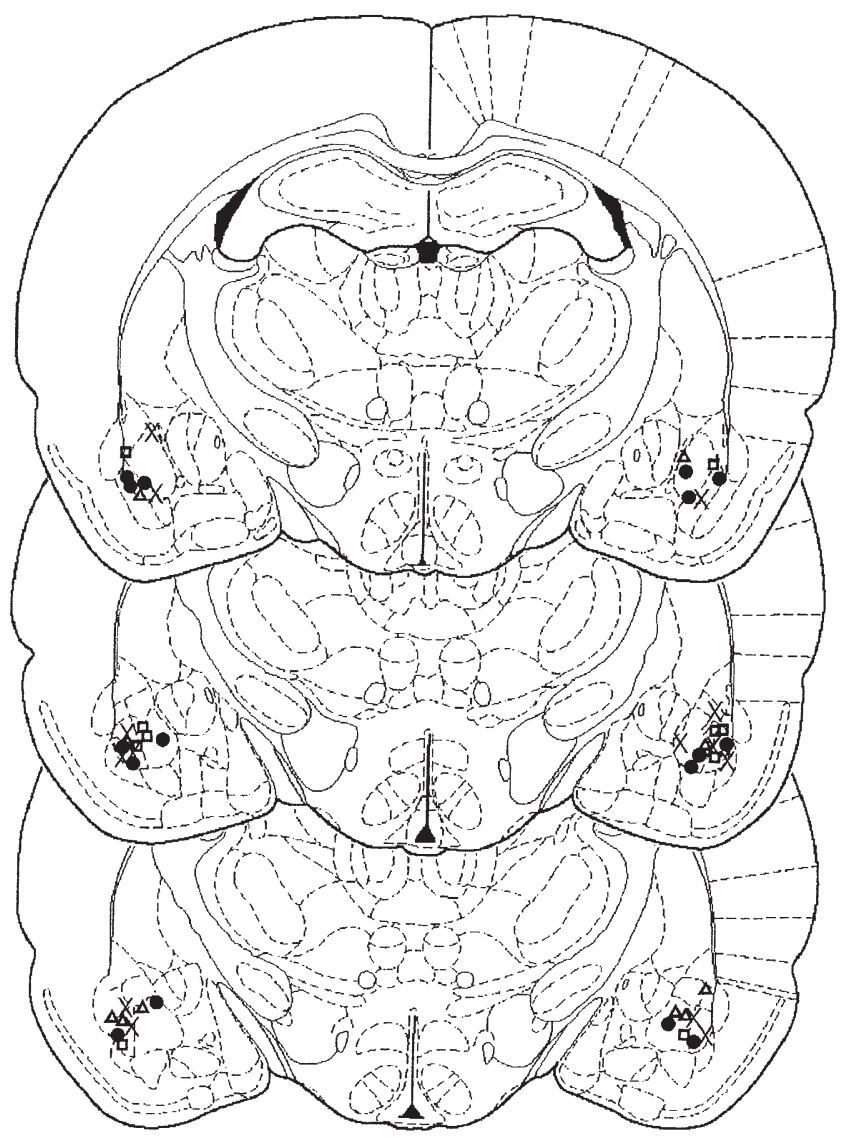

Figure 1. Location of injectors within the BLA. Schematic representation of the brain at three rostro-caudal levels $(-2.30,-2.56$, and -2.80 $\mathrm{mm}$ from bregma). All rats included in the statistical analyses had injectors placed bilaterally in the BLA $(X=$ PBS reactivated; $\bullet=$ DCS reactivated; $\square=$ PBS nonreactivated; $\triangle=$ DCS nonreactivated).

exposure to a cocaine-associated CS increased subsequent cocaine seeking behavior maintained by that CS. Moreover, the expression of the reconsolidation-associated gene zif268 in the amygdala was also elevated by DCS infusion coupled with CS re-exposure. Both of these effects were critically dependent upon rats being reexposed to the cocaine CS shortly after DCS infusion. We have previously demonstrated both that paired presentations of CS and reward are necessary for the acquisition of conditioned reinforcing properties (Parkinson et al. 2005), and that re-exposure to contextual and other stimuli are insufficient to reactivate the CScocaine memory (Lee et al. 2006a). Therefore, the present results most likely reflect an effect of DCS to potentiate the reconsolidation of the CS-cocaine memory, thereby enhancing the appetitive properties of the CS and increasing cue-induced cocaine seeking.

DCS has been shown to potentiate a number of memory plasticity processes, including initial memory acquisition/consolidation (Monahan et al. 1989; Land and Riccio 1999; Kalisch et al. 2008), memory extinction (Walker et al. 2002; Ledgerwood et al. 2003), and memory reconsolidation (Lee et al. 2006b). Moreover, the effect of DCS here was memory reactivation dependent and hence not a result of an acute effect upon behavior. Therefore, the elevation of subsequent cue-induced cocaine seeking reflects an enhancement of CS-cocaine memory expression. The delay of $3 \mathrm{~d}$ between the end of self-administration training and DCS infusion ensured that initial consolidation processes were complete, and hence the effect of DCS is more likely be related to memory extinction or reconsolidation, of which only a potentiation of 
A

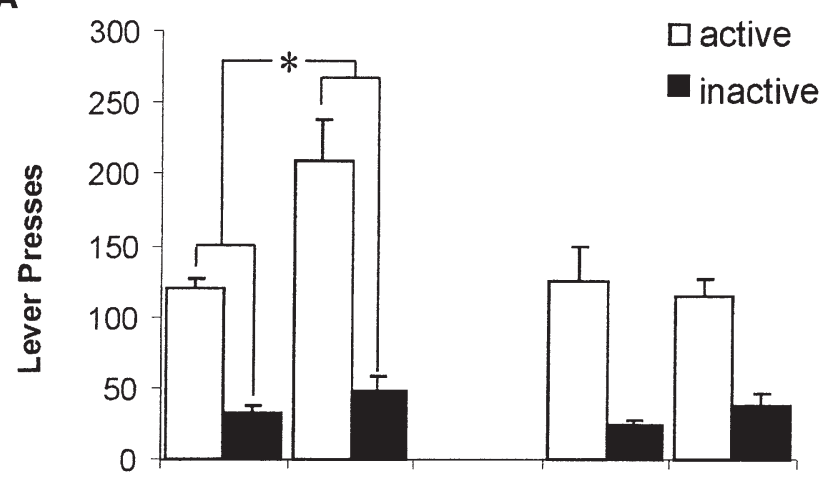

B

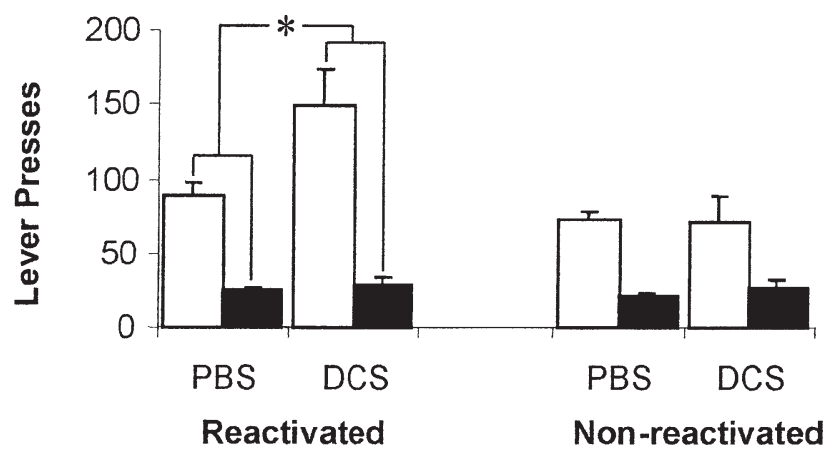

Figure 2. Effect of prereactivation intra-BLA DCS on cocaine seeking. The number of active and inactive lever presses during the 60-min tests are presented for rats infused $3 \mathrm{~d}$ and tested $6 \mathrm{~d}$ after the end of selfadministration training $(A)$ in both the reactivated (PBS $n=8$, DCS $n=7$ ) and nonreactivated (PBS $n=6$, DCS $n=5$ ) conditions. DCS increased subsequent active lever responding across both bins in a reactivationdependent manner, and the elevation was observed in a further test $24 \mathrm{~h}$ later $(B)$. Data presented as mean + SEM. An asterisk $\left(^{*}\right)$ represents a significant DCS $\times$ Lever interaction, $P<0.05$.

memory reconsolidation can account for the present results. Therefore, the behavioral evidence strongly indicates that DCS infusion into the BLA can potentiate drug memory reconsolidation to elevate subsequent drug seeking, at least under certain circumstances.

The cellular data obtained in the present study provides further evidence that DCS elevation of NMDA receptormediated glutamate transmission enhances cocaine seeking through the potentiation of drug memory reconsolidation. The expression of the immediate-early gene zif268 has been shown in several settings to be a critical and causal mechanism in memory reconsolidation. The expression of zif268 at both the mRNA and protein levels is upregulated by stimulus re-exposure that induces the reconsolidation of aversive contextual fear (Hall et al. 2001; Lee et al. 2004), discrete cue fear (Hall et al. 2001), and conditioned withdrawal memories (Hellemans et al. 2006), as well as appetitive CS-cocaine associations (Thomas et al. 2003). Moreover, functional reduction of zif268 expression in transgenic mice or through the local intracerebral infusion of zif268 antisense oligodeoxynucleotides impairs the reconsolidation of several types of memory (Bozon et al. 2003; Lee et al. 2004, 2005, 2006a; Hellemans et al. 2006). Of special importance is the observation that zif 268 expression in the BLA is correlated with, and necessary for, the reconsolidation of CS-cocaine memories (Thomas et al. 2003; Lee et al. $2005,2006 a$ ), and hence zif268 protein levels in the BLA are a cellular marker for drug memory reconsolidation. Here zif268 protein levels in the BLA were greatly increased by intra-BLA DCS infusion in conjunction with memory reactivation, strongly suggesting that DCS acts to enhance the cellular mechanisms of drug memory reconsolidation, resulting in the observed elevation of drug seeking behavior at a later test. Importantly, this potentiation of zif268 expression was not observed when DCS was infused in the absence of a memory reactivation session, thus demonstrating that the impact of DCS conforms to the reactivation-dependent criterion of memory reconsolidation effects (Lewis 1979; Dudai 2004).

Previous studies have demonstrated that treatment with DCS in conjunction with nonreinforced CS re-exposure results in a subsequent decrease in drug-related behavior, consistent with an enhancement of drug memory extinction, leading to the suggestion that DCS might be used in conjunction with cue exposure therapy as a treatment strategy for addiction (Botreau et al. 2006; Kelley et al. 2007). However, these studies used a drug conditioned place preference procedure, involving only four experimenter-administered intraperitoneal injections of cocaine. The present study uses a more translationally relevant model of chronic cocaine selfadministration with hundreds of pairings of the CS with intravenous cocaine. Therefore, the effect of DCS to increase subsequent cue-induced cocaine seeking may reflect more accurately the likely outcome of a DCS-based treatment strategy, given the chronic nature of drug exposure characteristic of addiction. Moreover, it may be the case that DCS combined with cue exposure may not be effective in prolonging abstinence and preventing relapse, as this approach may, in fact, further strengthen the detrimental impact of exposure to drug-associated stimuli, making relapse more likely.

The different levels of drug memory strength between the conditioned place preference and self-administration studies can explain the contrasting outcomes observed with DCS. The strength of conditioning is an important factor in determining whether memory-modulating treatments impact upon reconsolidation or extinction, with stronger training biasing toward memory reconsolidation (Eisenberg et al. 2003). Therefore, it is not surprising that DCS enhanced drug memory reconsolidation here,
A

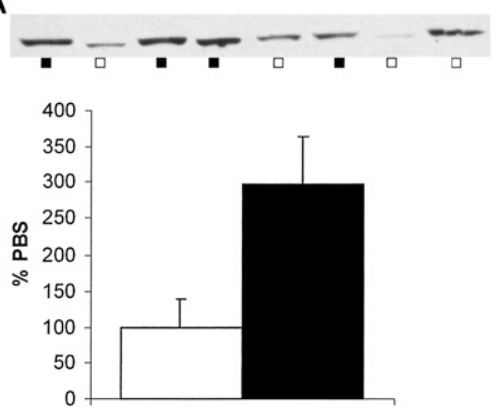

Figure 3. Effect of prereactivation intra-BLA DCS on zif268 protein levels in the BLA. The images of the gels were quantified and normalized to give a measure of zif268 protein relative to control PBSinfused rats. DCS increased the levels of zif268 protein $2 \mathrm{~h}$ after memory reactivation $[(A) ; n=4$ per group], but not at the equivalent time point in the nonreactivated condition $[(B) ; n=3$ per group]. Data presented as mean + SEM.
B

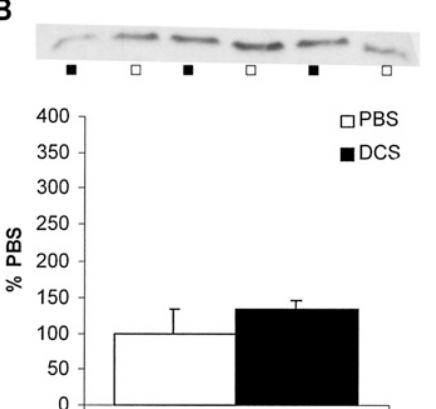


while potentiating extinction in the more weakly conditioned place preference studies, especially given that we have previously shown DCS to have bidirectional mnemonic effects in a fear conditioning procedure (Lee et al. 2006b). Future studies will be required to clarify parametrically the impact of memory strength and also the extent of cue exposure upon the effects of DCS. In addition, while the present study focused upon the Pavlovian conditioned reinforcing effects of drug-associated stimuli, due to their importance in relapse, the effect of DCS upon instrumental responding is also of interest. Any impact of DCS upon instrumental memories is likely to be mediated by neural loci beyond the amygdala, and so it will be important to establish how systemic, rather than localized intracerebral, injections of DCS affect the many drug-related memories that contribute to drug seeking behavior. The present results do not invalidate the potential application of DCS in the future treatment of drug addiction. However, they demonstrate clearly that its use must be carefully controlled, as there is the distinct likelihood that memory reconsolidation, rather than extinction, processes will be potentiated, leading to the deleterious consequence of promoting the conditioned elicitation of drug seeking behavior and relapse.

\section{Acknowledgments}

This work was supported by a grant from the U.K. Medical Research Council (Program Grant No. 9536855) and was conducted within the MRC/Wellcome Trust Behavioural and Clinical Neuroscience Institute.

\section{References}

Botreau, F., Paolone, G., and Stewart, J. 2006. D-Cycloserine facilitates extinction of a cocaine-induced conditioned place preference. Behav. Brain Res. 172: 173-178.

Bozon, B., Davis, S., and Laroche, S. 2003. A requirement for the immediate early gene zif268 in reconsolidation of recognition memory after retrieval. Neuron 40: 695-701.

Brunet, A., Orr, S.P., Tremblay, J., Robertson, K., Nader, K., and Pitman, R.K. 2007. Effect of post-retrieval propranolol on psychophysiologic responding during subsequent script-driven traumatic imagery in posttraumatic stress disorder. J. Psychiatr. Res. 42: 503-506.

Burns, L.H., Robbins, T.W., and Everitt, B.J. 1993. Differential-effects of excitotoxic lesions of the basolateral amygdala, ventral subiculum and medial prefrontal cortex on responding with conditioned reinforcement and locomotor-activity potentiated by intraaccumbens infusions of D-amphetamine. Behav. Brain Res. 55: 167-183.

Childress, A.R., Mozley, P.D., McElgin, W., Fitzgerald, J., Reivich, M., and O'Brien, C.P. 1999. Limbic activation during cue-induced cocaine craving. Am. J. Psychiatry 156: 11-18.

Corbit, L.H. and Balleine, B.W. 2005. Double-dissociation of basolateral and central amygdala lesions on the general and outcome-specific forms of pavlovian-instrumental transfer. J. Neurosci. 25: 962-970.

de Wit, H. and Stewart, J. 1981. Reinstatement of cocaine-reinforced responding in the rat. Psychopharmacology 75: 134-143.

Di Ciano, P. and Everitt, B.J. 2001. Dissociable effects of antagonism of NMDA and AMPA/KA receptors in the nucleus accumbens core and shell on cocaine-seeking behavior. Neuropsychopharmacology 25: $341-360$.

Dudai, Y. 2004. The neurobiology of consolidations, or, how stable is the engram? Annu. Rev. Psychol. 55: 51-86.

Ehrman, R.N., Robbins, S.J., Childress, A.R., and O'Brien, C.P. 1992. Conditioned responses to cocaine-related stimuli in cocaine abuse patients. Psychopharmacology 107: 523-529.

Eisenberg, M., Kobilo, T., Berman, D.E., and Dudai, Y. 2003. Stability of retrieved memory: Inverse correlation with trace dominance. Science 301: 1102-1104.

Everitt, B.J., Cardinal, R.N., Parkinson, J.A., and Robbins, T.W. 2003. Appetitive behavior: Impact of amygdala-dependent mechanisms of emotional learning. Ann. NY Acad. Sci. 985: 233-250.

Fuchs, R.A., Tran-Nguyen, L.T.L., Specio, S.E., Groff, R.S., and Neisewander, J.L. 1998. Predictive validity of the extinction/reinstatement model of drug craving. Psychopharmacology 135: 151-160.

Gawin, F.H. and Kleber, H.D. 1986. Abstinence symptomatology and psychiatric diagnosis in cocaine abusers. Clinical observations. Arch. Gen. Psychiatry 43: 107-113.
Grimm, J.W., Hope, B.T., Wise, R.A., and Shaham, Y. 2001. Neuroadaptation. Incubation of cocaine craving after withdrawal. Nature 412: $141-142$.

Hall, J., Thomas, K.L., and Everitt, B.J. 2001. Cellular imaging of zif268 expression in the hippocampus and amygdala during contextual and cued fear memory retrieval: Selective activation of hippocampal CA1 neurons during the recall of contextual memories. J. Neurosci. 21: 2186-2193.

Hellemans, K.G.C., Everitt, B.J., and Lee, J.L.C. 2006. Disrupting reconsolidation of conditioned withdrawal memories in the basolateral amygdala reduces suppression of heroin seeking in rats. J. Neurosci. 26: 12694-12699.

Kalisch, R., Holt, B., Petrovic, P., De Martino, B., Klöppel, S., Büchel, C., and Dolan, R.J. 2008. The NMDA agonist D-cycloserine facilitates fear memory consolidation in humans. Cereb. Cortex. doi: 10.1093/cercor/ bhn076.

Kelley, J.B., Anderson, K.L., and Itzhak, Y. 2007. Long-term memory of cocaine-associated context: Disruption and reinstatement. Neuroreport 18: $777-780$.

Land, C. and Riccio, D.C. 1999. D-cycloserine: Effects on long-term retention of a conditioned response and on memory for contextual attributes. Neurobiol. Learn. Mem. 72: 158-168.

Ledgerwood, L., Richardson, R., and Cranney, J. 2003. Effects of Dcycloserine on extinction of conditioned freezing. Behav. Neurosci. 117: 341-349.

LeDoux, J.E. 2000. Emotion circuits in the brain. Annu. Rev. Neurosci. 23: $155-184$.

Lee, J.L.C., Everitt, B.J., and Thomas, K.L. 2004. Independent cellular processes for hippocampal memory consolidation and reconsolidation. Science 304: 839-843.

Lee, J.L.C., Di Ciano, P., Thomas, K.L., and Everitt, B.J. 2005. Disrupting reconsolidation of drug memories reduces cocaine-seeking behavior. Neuron 47: 795-801.

Lee, J.L.C., Milton, A.L., and Everitt, B.J. 2006a. Cue-induced cocaine seeking and relapse are reduced by disruption of drug memory reconsolidation. J. Neurosci. 26: 5881-5887.

Lee, J.L.C., Milton, A.L., and Everitt, B.J. 2006b. Reconsolidation and extinction of conditioned fear: Inhibition and potentiation. J. Neurosci. 26: 10051-10056.

Lewis, D.J. 1979. Psychobiology of active and inactive memory. Psychol. Bull. 86: 1054-1083.

Lu, L., Grimm, J.W., Hope, B.T., and Shaham, Y. 2004. Incubation of cocaine craving after withdrawal: A review of preclinical data. Neuropharmacology 47: Suppl 214-226.

Meil, W.M. and See, R.E. 1997. Lesions of the basolateral amygdala abolish the ability of drug associated cues to reinstate responding during withdrawal from self-administered cocaine. Behav. Brain Res. 87: 139-148.

Monahan, J.B., Handelmann, G.E., Hood, W.F., and Cordi, A.A. 1989. Dcycloserine, a positive modulator of the N-methyl-D-aspartate receptor, enhances performance of learning tasks in rats. Pharmacol. Biochem. Behav. 34: 649-653.

Nader, K. 2003. Memory traces unbound. Trends Neurosci. 26: 65-72.

O'Brien, C.P., Childress, A.R., Ehrman, R., and Robbins, S.J. 1998. Conditioning factors in drug abuse: Can they explain compulsion? J. Psychopharmacol. 12: 15-22.

Parkinson, J.A., Roberts, A.C., Everitt, B.J., and Di Ciano, P. 2005. Acquisition of instrumental conditioned reinforcement is resistant to the devaluation of the unconditioned stimulus. Q. J. Exp. Psychol. B 58: $19-30$.

Ressler, K.J., Rothbaum, B.O., Tannenbaum, L., Anderson, P., Graap, K., Zimand, E., Hodges, L., and Davis, M. 2004. Cognitive enhancers as adjuncts to psychotherapy: Use of D-cycloserine in phobic individuals to facilitate extinction of fear. Arch. Gen. Psychiatry 61: $1136-1144$.

Richardson, R., Ledgerwood, L., and Cranney, J. 2004. Facilitation of fear extinction by D-cycloserine: Theoretical and clinical implications. Learn. Mem. 11: 510-516.

Thomas, K.L., Arroyo, M., and Everitt, B.J. 2003. Induction of the learning and plasticity-associated gene zif268 following exposure to a discrete cocaine-associated stimulus. Eur. J. Neurosci. 17: 1964-1972.

Walker, D.L., Ressler, K.J., Lu, K.T., and Davis, M. 2002. Facilitation of conditioned fear extinction by systemic administration or intraamygdala infusions of D-cycloserine as assessed with fear-potentiated startle in rats. J. Neurosci. 22: 2343-2351.

Whitelaw, R.B., Markou, A., Robbins, T.W., and Everitt, B.J. 1996. Excitotoxic lesions of the basolateral amygdala impair the acquisition of cocaine-seeking behaviour under a second-order schedule of reinforcement. Psychopharmacology 127: 213-224.

Received August 11, 2008; accepted in revised form October 23, 2008. 


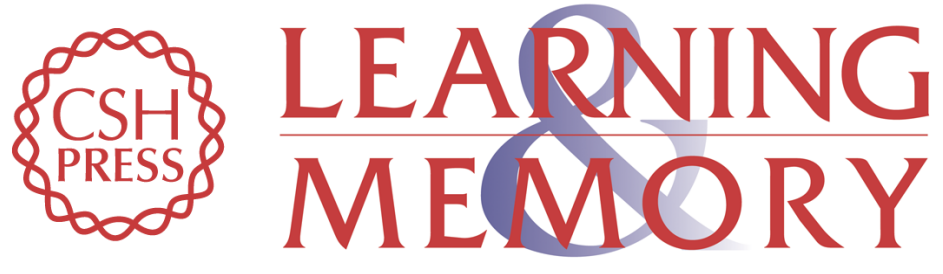

\section{D-cycloserine potentiates the reconsolidation of cocaine-associated memories}

Jonathan L.C. Lee, Richard J. Gardner, Victoria J. Butler, et al.

Learn. Mem. 2009, 16:

Access the most recent version at doi:10.1101//m.1186609

References This article cites 38 articles, 9 of which can be accessed free at:

http://learnmem.cshlp.org/content/16/1/82.full.html\#ref-list-1

License

Email Alerting Receive free email alerts when new articles cite this article - sign up in the box at the Service top right corner of the article or click here. 